\title{
PS19
}

\section{Microseismic Monitoring and Subseismic Fault Detection in an Underground Gas Storage}

\section{D.A. Kraaijpoel* (KNMI), D.A. Nieuwland (Taqa Energy BV) \& B. Dost} (KNMI)

\section{SUMMARY}

A natural gas field with an induced seismic history is being converted to an underground gas storage. Microseismic monitoring with a downhole tool detects hundreds of microseismic events. The events delineate a subseismic fault that coincides with a previously interpreted flow baffle. 


\section{Introduction}

The Bergermeer field is a natural gas reservoir located in a densely populated area in the NorthWestern part of the Netherlands (see Figure 1a). The field has been in production from 1970 to 2007. Currently, the field is being converted to an Underground Gas Storage (UGS) facility for natural gas with an operational volume of $4.1 \mathrm{bcm}$ on top of a cushion of $4.6 \mathrm{bcm}$.

\section{Geology}

The reservoir geometry is defined by a horst structure at $2 \mathrm{~km}$ depth with top and side seals consisting of a series of evaporites from the Zechstein formation. The reservoir rock is a sandstone of Permian age from the Slochteren formation. A central fault zone divides the field in two blocks that are partly pressure separated. The throw of the central fault decreases towards the north to below standard 3D seismic resolution (throws of about $25 \mathrm{~m}$ ), see Figure $1 \mathrm{~b}$.

\section{Seimicity}

During the production phase, two pairs of widely felt and slightly damaging earthquakes with local magnitudes between 3.0 and 3.5 have been induced (e.g., van Eck et al., 2004). After the first pair of events in 1994 a local 3-station seismic network of shallow borehole sensors was installed. This network, with a local detection threshold in the order of magnitude 1, has not detected any local seismicity apart from the second pair of strong events in 2001 . The events have been located near the tip of the central fault (see Figure 1b).

a)

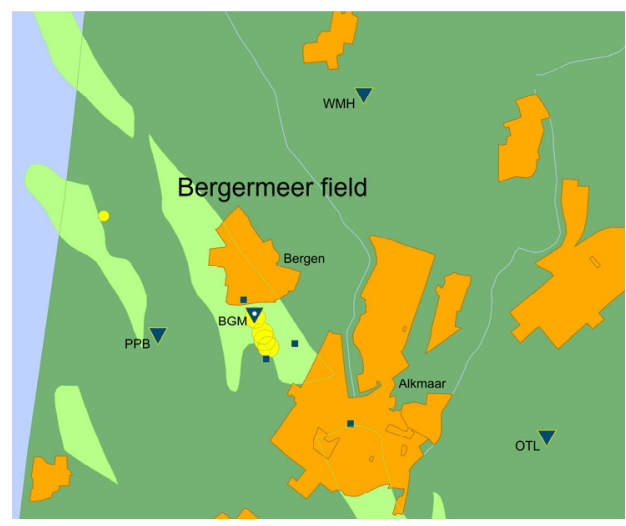

b)

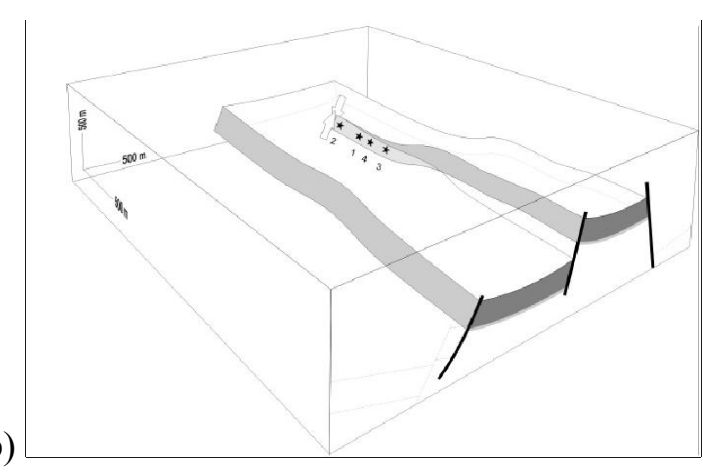

Figure 1 a) The Bergermeer field (light green) is located beneath a densely populated area. Figure shows the local seismic network (WMH, PPB, OTL), the monitoring array (BGM) and the historic induced events (yellow dots). b) Schematic reservoir geometry including historic events.

Considering the historical events, a critical aspect of the UGS operation is the mitigation of further induced seismicity. Geomechanical modelling has pointed out that the most likely effect of gas injection is a stabilisation of the central fault (B.Wassing, TNO, personal communication). The reservoir pressure had dropped from the original 228 bar to 58 bar during the first and 22 bar during the second pair of events. The cushion gas has in the meantime increased the pressure back to 70 bar (December 2012) without further seismicity.

\section{Microseismic Monitoring}

As part of the mitigation strategy a vertical downhole seismic array has been installed at reservoir depth $(2 \mathrm{~km})$ to monitor microseismic activity. The array consists of six $3 \mathrm{C}$ sensors with a spacing of $10 \mathrm{~m}$. 
During the 2.5 years of operation of the monitoring array up till now (January 2013) around 220 events have been located, with moment magnitudes mostly between -3 and -2 . The last few months the event rate has decreased considerably, suggesting a confirmation of the geomechanical modelling results.

A large fraction of the microseismic events clusters in an area to the east of the central fault tip. In October 2011 a swarm of more than 50 events occurred in that area. 3D-Visualisation revealed that he events line-up along planar surface at a high angle to the central fault (see Figure 2). Log correlations and reservoir simulations had already suggested a gas flow baffle in this area that could be associated to a small fault. However, the fault could not be identified on the available 3D seismic. Later reprocessing of the seismic made interpretation of smaller structural elements possible and this small fault could now also be interpreted. The location of the fault is in a small anticlinal curve, in an outer arc extension position. A geomechanical analysis of the effect of this micro faulting indicates that it has a small stabilizing effect on the much larger central fault.

a)
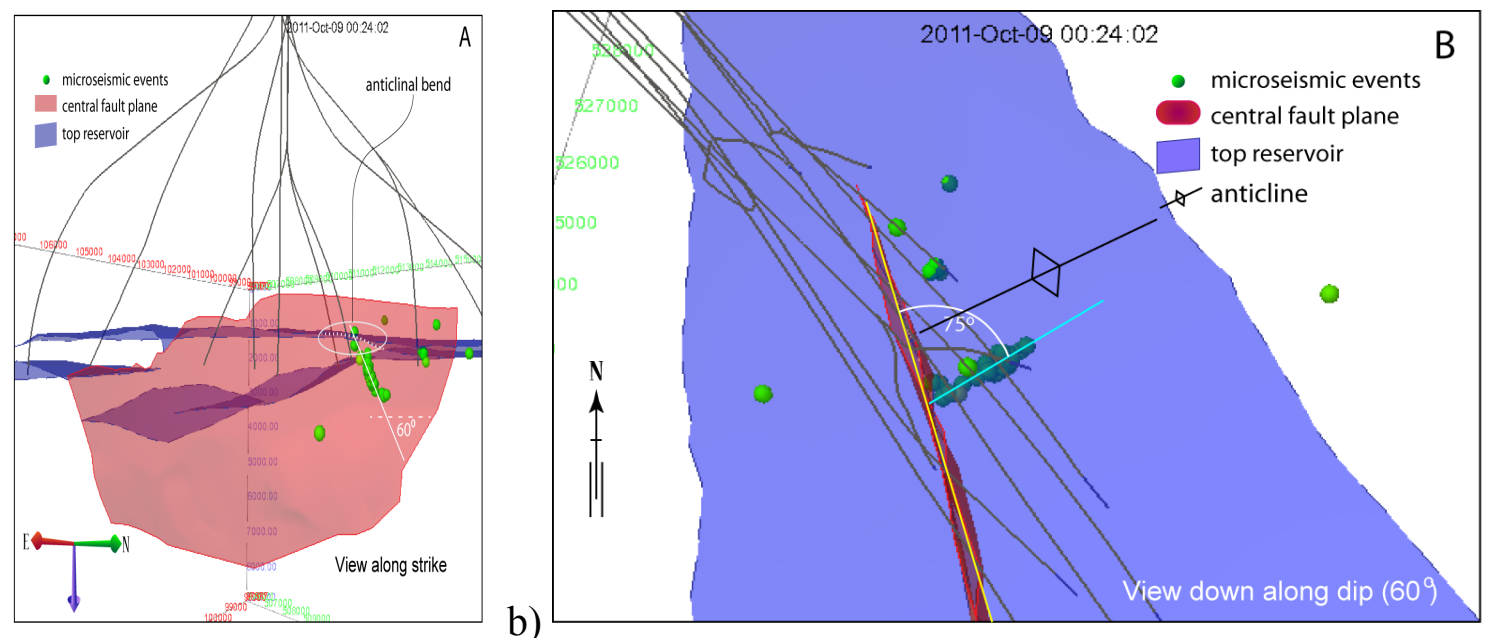

Figure 2 Subsurface views of the reservoir with emphasis on the cluster of the microseismic events detected by the downhole monitoring tool. The events delineate a hitherto uninterpreted fault and flow baffle. a) view along strike, b) view along dip

\section{Conclusions}

The microseismic monitoring in the Bergermeer UGS seems to corroborate the stabilizing effect of gas injection on the seismogenic central fault. Also, the monitoring has revealed a (nearly) subseismic fault and flow baffle. This revelation has been used in the planning of new injection wells. The availability of microseismic monitoring data therefore enables improved reservoir management of the gas storage.

\section{Acknowledgements}

We thank Brecht Wassing and Bogdan Orlic from TNO for sharing their results on geomechanical modelling.

\section{References}

van Eck, T., Goutbeek, F., Haak, H. and Dost, B. [2004] Seismic hazard due to small shallow induced earthquakes. KNMI Scientific Report; WR 2004-01. 